\title{
Épicas barriales: lo público-político vivo
}

\author{
Ariel Gravano
}
Consejo Nacional de Investigaciones Científicas y Técnicas (Conicet), Universidad Nacional del Centro de la Provincia de Buenos Aires (Unicen), Buenos Aires, Argentina arielgravano14@gmail.com

\begin{abstract}
Resumen: El objetivo del trabajo apunta a responder el interrogante por los sentidos políticos de las narrativas barriales que se definen como épicas, en contextos de luchas por el espacio urbano y por consumos colectivos. Se abarcan casos en una región metropolitana (ciudad de Buenos Aires) y una ciudad media (del centro de la provincia de Buenos Aires), en un lapso que va desde la década del sesenta del siglo XX hasta el presente. La base metodológica etnográfica del enfoque se proyecta a casos de construcción de identidades barriales y procesos de movilización y participación. A partir de la teoría de los movimientos sociales y de lo urbano estructural-significacional, se aborda la relación entre la concepción de lo público y la ciudadanía desde la crítica al clásico prisma idealista-burgués y a las asunciones del vecinalismo culturalista. El análisis interpretativo se posiciona en una dialéctica de lo público -desde el concepto de Carlos Marx y en debate con la clásica posición idealista- hacia lo que definimos como lo político vivo.

Palabras clave: Épica barrial; luchas por el espacio urbano; etnografía urbana; dialéctica de lo público; lo político vivo.
\end{abstract}

Neighborhood epics: the public-political alive

Abstract: The aim of this work is to comprehend the political sense of neighborhood narratives that are defined as epic stories, in the context of struggles for urban space and public services. The set of cases displayed include a metropolitan region (Buenos Aires) and a middle range city (in the center of the province

Cuadernos de Antropología

Julio-Diciembre 2016, 26(2), 1-25

DOI: $10.15517 /$ cat.v26i2.27304

Recibido: 23-08-2016 / Aceptado: 21-10-2016 / Publicado: 13/12/2016

Revista del Laboratorio de Etnología María Eugenia Bozzoli Vargas

Escuela de Antropología, Universidad de Costa Rica

http://revistas.ucr.ac.cr/index.php/antropologia

ISSN 2215-356X 
of Buenos Aires) over a period of time ranging from the 1960s to the present. The methodological basis of the approach is the ethnography of social processes of mobilization, participation and construction of neighborhood identities. From the theory of social movements and the significational-structural urban phenomena, we study the relationship between conceptions of public and citizenship. We do so with a critical point of view of the classical bourgeois idealistic prism and the culturalist vecinalismo. The interpretive analysis is positioned in the dialectics of the public -according to the theoretical frame of Karl Marx- and the discussion of the classical idealist position. We define this dialectics as the political alive.

Keywords: Neighborhood epics; struggles for urban space; urban ethnography; dialectic of the public; the political alive.

\section{Introducción}

El eje de este trabajo es el interrogante por los sentidos políticos de las narrativas barriales que definimos como épicas en contextos de luchas por el espacio urbano. A partir de la teoría de los movimientos sociales abordamos la relación entre la concepción de lo público y la ciudadanía desde la crítica al clásico prisma idealista-burgués y a las asunciones del vecinalismo culturalista. La base etnográfica del enfoque toma casos de construcción de identidades barriales y procesos de movilización y participación; y el análisis se posiciona en una dialéctica de lo público -desde el concepto de Carlos Marx y en debate con la clásica posición idealista- hacia el concepto de lo político vivo.

\section{Movimientos urbano-barriales}

Los movimientos sociales urbanos (MSU) suelen concebirse como resultado de luchas por consumos colectivos en la esfera de la reproducción (vivienda, infraestructura, equipamientos, servicios públicos) o lo que algunos denominamos la ciudad en su valor de uso, y se referencian principalmente en el espacio público'. Sus luchas, como parte de los "nuevos movimientos sociales", son caracterizadas como coyunturales, efímeras y propias de sectores socialmente heterogéneos. Sus reivindicaciones son acotadas a esos

1 A los MSU así los definimos en un trabajo reciente: "La ciudad, como 'depósito de capital fijo acumulado', summum de la producción material y simbólica humana, muestrario del máximo desarrollo tecnológico, constituida en sí misma como "valor de uso complejo al servicio del capital" (Portillo, 1991), debido a su aprovechamiento como "efecto útil de aglomeración" (Topalov, 1979, p. 9) de servicios e infraestructura para la actividad industrial y, sobre todo, componente básico de la reproducción necesaria de la sociedad moderna en su conjunto, incluye sus dialécticas de integración y desagregación, cooperación y conflicto, orden y "desvío", conservación y utopía, socializaciones y apropiaciones, derechos y conculcaciones, universalismos y privatismos [..] inherentes al proceso urbano capitalista que no garantiza la reproducción y racionaliza su "demanda solvente anticipada" (Castells, 1987, p.19) por medio de la propia ciudad convertida en mercancía. Es lógico pensar, en consecuencia, que si se considera lo urbano como un insumo necesario para garantizar la reproducción material y social, las condiciones de apropiación privada y desigual de los resultados del proceso socializador de la ciudad provoquen reacciones sociales que la tomen como objeto de lucha y no solo como arena de lucha y que emerja la reivindicación de la ciudad como un derecho" (Gravano, 2015, p. 103).

Cuadernos de Antropología 2016, 26(2), 1-25 / ISNN 2215-356X

http://revistas.ucr.ac.cr/index.php/antropologia 
consumos y servicios, enfrentando al estado y/o negociando con él, con el propósito limitado a esos logros, los que una vez obtenidos suelen hacer decaer la envergadura de la lucha o al menos su notoriedad. Por eso se los coloca teóricamente como una manifestación hasta gestual de la posmodernidad, en una dimensión que podría tipificarse como de corto alcance en el tiempo y en su trascendencia política ${ }^{2}$.

En rigor, se los comenzó a definir en contraposición con los movimientos políticos modernos clásicos (de partidos, sindicatos y gobiernos), cuyos propósitos apuntan al control del Estado y la toma del poder, se desarrollan en la esfera de la producción material y social, en una escala de duración tan prolongada como esa cuestión del poder y, por lo tanto, nítidamente "históricos" en cuanto a su alcance de totalidad trascendente.

Entre los movimientos urbanos, tipificados así desde hace más de tres décadas, se distinguen los que se referencian en los barrios. En algunos casos los barrios son tomados como meros escenarios y en otros como prenda concreta de la lucha por el espacio urbano, categoría que ha perdido vigencia discursiva en los últimos años, habida cuenta del auge de la ligera y no problematizada muletilla del espacio (público) urbano más "en disputa" que en términos estructurales y más en torno a una hiperponderación tanto de la "sociedad civil" cuanto de una ciudadanía abstracta que del poder político transformador.

\section{Épicas barriales}

En estas narrativas se pueden encontrar recurrentes imágenes de heroísmo colectivo con respecto a situaciones críticas extremas, de las cuales los personajes individuales y el colectivo mismo lograron "salir" mediante prácticas o acciones vividas como hazañas. Ambos atributos compondrían lo que podríamos concebir como épicas barriales ${ }^{3}$.

¿Por qué colocamos a la épica barrial como objeto de análisis del carácter político de los movimientos barriales? Comencemos por definirla. Épica barrial es aquella producción simbólica que compone un imaginario social cuyos contenidos narrativos incluyen hitos y procesos reales sentidos como hazañas heroicas a cargo de actores colectivos barriales en contextos de luchas por el espacio urbano, y que a su vez funcionan como indicadores de identidades construidas en torno a esas representaciones.

Esta relación mutua entre ethos y epos (identidad y épica) se inscribe en un eje referencial que sitúa a la narrativa en una dimensión temporal y simbólica, en principio como cronos, pero valorizado en términos contrastantes, entre épocas simbólicas opuestas, más que cronológicas. Esta será nuestra hipótesis de

2 Salvo cuando se transforman en movimientos políticos, en un sentido clásico y estricto del concepto, como aconteció con el Partido de los Trabajadores en Brasil.

3 Tomamos la definición de épos de Vladimir Propp, que centra en lo hazañoso y lo heroico como los ejes centrales de la narrativa, que "no tiene carácter individual, sino popular y nacional, y de clase" (Propp, 1983, p. 12). 
partida, de acuerdo con nuestras investigaciones sobre lo barrial como producción ideológico-simbólica, donde hemos definido a lo barrial como un conjunto de valores más que un mero referente urbano espacial particular (el barrio) (Gravano, 2003).

Podríamos agregar, entonces, al interrogante sobre los sentidos políticos que cumpliría esa narrativa épica en el desarrollo de esos movimientos, tres cuestiones que discuten 1) el carácter de clase de estos movimientos, 2) los sentidos de ciudadanía que desencadenan en relación con la esfera pública en torno a asunciones de tipo vecinalista de parte del Estado y de los actores sociales y 3) con referencia concreta a una de las variables más invocadas, como es la participación, en relación con sus condiciones estructurales y su valor como transformación política.

\section{Viñetas épicas}

Mostraremos a continuación algunos retazos o viñetas de casos y procesos que seleccionamos porque referencian empíricamente los conceptos de este trabajo, ya que forman parte de un muestrario común prototípico de luchas por el derecho al espacio y a consumos colectivos urbanos -principalmente la vivienda-, en relación con el Estado y con incidencia y participación de partidos políticos junto a los movimientos, o dentro de ellos, con la cuestión de lo público, la sociedad civil y la ciudadanía, recurrentemente invocadas. Abarcan un lapso largo (desde mediados del siglo pasado hasta el presente) y se localizan en escalas que van desde el ámbito metropolitano de la ciudad de Buenos Aires al de un barrio periférico de una ciudad media de la Provincia de Buenos Aires.

Recorreremos, en primer lugar, el movimiento de sociedades vecinales "de fomento" de la ciudad de Buenos Aires durante la década del sesenta, caracterizado por el acentuado crecimiento de la alfombra urbana y sobre todo "sub"-urbana del llamado -en ese entonces- Gran Buenos Aires, o zona metropolitana, tomando una pequeña muestra de una investigación específica realizada en nuestros estudios barriales y trabajos de intervención en organizaciones populares, entre 1985 y 1998 (Gravano, 2003).

En segundo lugar, tomaremos el movimiento de habitantes de las denominadas villas miseria metropolitanas, que en la década del sesenta eran tipificadas como asentamientos irregulares y caóticos de la marginalidad urbana: sin acceso en principio a los servicios públicos, con viviendas precarias, de auto-construcción y dispuestas en desorden. Además, formalmente ilegales, por ocupar terrenos fiscales o privados y no situarse económicamente dentro del mercado inmobiliario de la ciudad "normal", perseguidos y estigmatizados desde el imaginario hegemónico y estatal, con localización de fuerza de trabajo no especializada, inmigrante en principio de la Argentina interior (mediados de la década de 1940) de provincias, luego de países limítrofes y posteriormente con más de ocho generaciones propiamente villeras, que conformarían el movimiento villero, que referimos en sus orígenes. 
En tercer término, mostramos la toma (o intrusión), en este caso planificada de terrenos privados y fiscales del con-urbano bonaerense (ex-Gran Buenos Aires) para formar barrios (organizados en sistema de cuadrícula en damero y con calles interiores, no como las villas, donde las viviendas se hacinan con meros pasillos entre ellas) del movimiento de trabajadores sin vivienda encabezado por algunos curas de la iglesia católica, luego de la expulsión de los villeros de la ciudad de Buenos Aires durante la dictadura cívicomilitar 1976-1983, dentro de nuestras indagaciones barriales ya citadas.

Pasamos luego a una breve viñeta de participación ciudadana, en donde intervinimos y de donde tomamos el testimonio, durante la crisis nacional de principios del siglo $\mathrm{XXI}^{4}$.

Y, finalmente el ejemplo tomado de nuestro trabajo de campo actual (2015-2016) en un barrio periférico de la ciudad de Olavarría, provincia de Buenos Aires (100 000 habitantes, preponderantemente agroindustrial), con una población de vecinos que lograron, mediante luchas a partir de la crisis 2001-2002, obtener facilidades para participar en la construcción de su propio barrio ${ }^{5}$.

\section{El fomentismo de la suburbanización}

"Los barrios recién se creaban... el Gran Buenos Aires era todo descampado y de repente, a pulmón, crecían los barrios", don Carlos G., a sus 80 recién cumplidos, abría los brazos ilustrando con emotividad la ampliación de la urbanización del Gran Buenos Aires. Una noche de abril de 1993 recordaba don Carlos el movimiento vecinal de fines de los 50 y principios de los 60 , cuando él y otros hijos de inmigrantes europeos militaban en sociedades de fomento.

Era como una ola que luego se perdía, a medida que se lograba lo que se reclamaba... Algunos se quejaban de que se metiera la política, bah, los partidos políticos. Y yo estaba en un partido, pero no hacía política en el movimiento ${ }^{6}$.

4 Referimos a la eclosión de manifestaciones populares masivas en diciembre de 2001 contra los efectos de las políticas neoliberales y la crisis político-institucional que produjo la sucesión inédita de cinco presidentes en menos de un mes (ver https:// es.wikipedia.org/wiki/Crisis_de_diciembre_de_2001_en_Argentina).

5 El proyecto actual lleva por título "Antropología de ciudades medias del centro bonaerense: sistema urbano, imaginarios sociales y tramas de poder". (Conicet) desde el Núcleo de Investigación "Producciones e investigaciones comunicacionales y sociales de la ciudad intermedia" (Proincomsci, Unicen) (2015-2018).

6 Salvo que se indique lo contrario, en este artículo los inter-textos, obtenidos por comunicación verbal de los actores en entrevista etnográfica o en contexto de observación participante, no tendrán más que las variables de base que el autor considera pertinentes para el concepto que se está desarrollando. 
Era la época en la que el tándem Frondizi-Alsogaray ${ }^{7}$ daba otra vuelta de tuerca en la dependencia económica explícita, luego de la llamada revolución libertadora, abordando el desequilibrio entre las migraciones hacia los grandes centros urbano-industriales y la provisión de las infraestructuras básicas de consumos colectivos para subsidiar al capital y que se acentuó en las zonas más urbanizadas. Este proceso pronto dio lugar a luchas urbanas de diverso tipo. En algunos casos, calladas e implícitas, cimentadas en el cotidiano reclamo, petitorio, queja o movilización por parte de sociedades de fomento o comisiones vecinales recientemente formadas; en otras ocasiones, convirtiéndose en verdaderas campañas masivas que aglutinaron a barrios enteros.

En 1962, desatada la lucha por el no pague la luz, contra los aumentos del ministro de economía, Federico Pinedo (del presidente Guido), abogado y representante de la compañía de electricidad de capitales extranjeros durante la Década Infame (1930-1943), sigue recordando don Carlos:

Una asamblea de tres mil personas se hace dentro de la sede de los Bomberos Voluntarios de La Matanza. Y repetíamos la consigna "No pague la luz, no pague la luz". Y desde un grupo de vecinos pide la palabra un santiagueño, de los miles de provincianos recién llegados al GBA:

-Todo eso está muy bien, señor, pero ¿me quiere decir qué luz quiere usté que no paguemos?, si nosotros nos alumbramos a kerosén....

De esta manera, interpretando la especificidad de la zona (40 000 personas alumbradas a kerosén), fue formado ahí mismo un movimiento bajo el rótulo Comisión por los problemas de la luz. Más de cincuenta actos multitudinarios en clubes e instituciones barriales fueron necesarios para movilizar a los vecinos y a la opinión pública. El movimiento contó con la solidaridad de los trabajadores de la empresa nacional de electricidad y el asesoramiento de ingenieros del Movimiento Pro-nacionalización de la C.A.D.E. (Compañía Argentina de Electricidad). Se compraron los postes y los cables y se realizó una gigantesca "colgada" de la luz, que consistió, en realidad, en aprovechar la energía que se perdía de los cables de alta tensión.

Mientras los vecinos organizados alzaban sus escaleras y hacían las conexiones oficialmente ilegales, un escribano del movimiento iba testimoniando el proceso de colgada masiva, autolegitimando las acciones. Desde la gobernación, se envió a la policía a reprimir, aunque ante la masividad de ese verdadero festival de escaleras, el comisario optó por hacer citaciones en forma individual, pero respondieron la totalidad de los vecinos e impusieron que se les tomara declaración a todos. Es que a alguien se le había ocurrido: "hagamos como en Fuente Ovejuna: "fuimos todos o no fue nadie... Ahí el intendente fue convencido para que actuara por encima de la Provincia y ordena a la policía dejar de lado el procedimiento”.

7 Arturo Frondizi y Álvaro Alsogaray, presidente y ministro de economía, respectivamente entre 1958 y 1962, impulsaron políticas desarrollistas neoliberales.

8 En Argentina se suele llamar "colgarse de la luz" al procedimiento alternativo, popular e ilegal de obtener la energía en forma clandestina mediante un cable informal.

Cuadernos de Antropología 2016, 26(2), 1-25 / ISNN 2215-356X

http://revistas.ucr.ac.cr/index.php/antropologia 
La provisión oficial del servicio público necesitó de la movilización ilegal, legitimada popularmente por cada barrio: "Pero eso luego decayó, porque lógicamente se fueron logrando las cosas, aunque ahora (refiriéndose al menemismo que estaba impulsando una política similar) los mismos intereses hacen lo mismo, pero la movilización aquella fue grandiosa" 9

\section{Movimientos villeros metropolitanos}

Según Oscar Oszlak (1991), el desorden urbano que caracterizó el crecimiento urbano de la Región Metropolitana de Buenos Aires (o Gran Buenos Aires), a partir de mediados de los años cuarenta, fue ocasionado fundamentalmente por la forma que adquirió la radicación industrial:

La zonificación espontánea, los loteos prematuros con fines especulativos, la radicación en una misma zona de viviendas e industrias malsanas o molestas... El nacimiento de las villas de emergencia en los alrededores de esas fábricas desordenadamente localizadas, no fue ajeno a la pasiva complicidad del estado (pp. 63-64).

Estuvo y sigue siendo bastante generalizado el uso de la categoría "respuestas estatales" a los problemas urbanos y sociales, como si estos fenómenos no fueran también gestados o instrumentados por parte del Estado. Son recordados aún por sus protagonistas los “operativos relámpago" de entonces, consistentes en la irrupción nocturna de efectivos policiales y/o militares y las topadoras municipales. Eran presentados públicamente como ejemplos de la tarea de "saneamiento urbano".

El origen de las organizaciones con que los villeros comenzaron a enfrentar sus problemas y su relación con el Estado fue categorizada por algunos como "espontánea” (Dávolos, Jabbaz y Molina, 1987). Pero podemos suscribir que luego de este origen, frente a obstáculos diarios, la población de las villas pasó a un nivel cualitativamente superior, si por esto entendemos una organización que supo nuclear las inquietudes de los diversos asentamientos y centralizar reivindicaciones y acciones. La Federación de Villas y Barrios de Emergencia de la Capital Federal se forma en 1958, siguiendo la política "de masas" del Partido Comunista Argentino:

Hace años que estamos trabajando juntos. Hicimos zanjas, tendimos cables para la luz, construimos desagües y veredas con nuestras propias manos, organizamos clubes, canchas de deportes y dispensarios. La escuela Bandera Argentina, de Retiro, es una de las más grandes de la Capital: tiene 1.400 alumnos. Y esa escuela se creó, por fin, después de años de petitorios de los padres y madres de la villa y de las comisiones vecinales.

9El testimonio fue tomado en un taller barrial del Movimiento Cooperativo de la Ciudad de Buenos Aires. 
Esto decía Pánfilo Genés, fundador de la FVBE, al periódico Acción, y resumía: "Nos quieren llevar a barrios transitorios, ¿para qué? transitorio es el lugar donde estamos viviendo” (1970, p. 5).

La coordinación con el movimiento obrero peronista durante aquellos primeros años había sido crucial para la organización villera, pero se debilitó con la dictadura militar de 1966 a 1973. Los testimonios de la época coinciden en un tiempo de lucha y participación del conjunto del arco ideológico en las villas, que luego cayó "en decadencia", adjudicándola cada quien a su historia personal y vinculándola con las consabidas represiones y extorsiones del Estado y principalmente de la policía con sus razias e incendios.

La oposición entre las soluciones definitivas reclamadas y los paliativos y erradicaciones por parte de los gobiernos se multiplicaron, ya que los sectores villeros veían cómo eran construidas viviendas que se proclamaban como destinadas para ellos y no eran adjudicadas a ningún poblador de villa, lo que explicaría el tópico de numerosos episodios de tomas de inmuebles antes de ser entregados.

En rigor, las villas se crearon más a partir de estrategias de los pobladores articuladas con el Estado de diversas maneras, como señalara Oszlack ${ }^{10}$, que a movimientos sociales organizados, ya que estos surgieron de y en las villas más a partir de las reivindicaciones por la efectivización y dignificación de la provisión de consumos colectivos urbanos, y que en principio estaban orientados a una visión barrial de la villa, nutriendo el imaginario de la consabida consigna: barrio sí, villa no.

\section{Las tomas del conurbano del ' 82}

La oposición a "hacer villa" ("queremos barrios") fue una de las claves de las "tomas de tierras de 1982" en San Francisco Solano, provincia de Buenos Aires. Por eso, el movimiento se organizó mediante un catastro clandestino y propio, donde el hilo y las estacas para marcar los terrenos fueron prioridad. Claro que la saga del auge y el declive también emergió al recordar: "En esa época había más participación", nos comentaba un vecino "fundador" de los "cuatro barrios" y protagonista de las tomas, porque "habia más solidaridad, más participación".

A nuestro alrededor, unas doscientas personas, entre vecinos de los barrios (la mayoría) y una cincuentena de militantes, celebraban los once años de aquellos acontecimientos que habían "pasado a la Historia" y por lo cual "uno puede sentirse orgulloso de ser de El Tala, de ir al centro de Solano y no tener miedo que te discriminen, aunque algunos lo siguen haciendo", como nos ilustraba Florencia, cuyos padres y ella a sus doce años habían "luchado y hecho las tomas", a las que les asignaba ese valor histórico.

10 Esto lo constataron diversos colegas (Bartolomé, 1984; Bellardi y De Paula, 1986; Guber, 2015; Hermitte y Boivin, 1984). 
En el modesto escenario erigido en la plaza a la que hubo que "pelear para que no pusieran ahí una casilla, porque no queríamos hacer villa", se representaba una obra de teatro dirigida por "Elvira, la vecina que lo viene haciendo año tras año, donde participan sesenta chicos". "Tenemos video de cómo amasan los diarios para hacer la cabeza de los muñecos, desde que están armando las topadoras, preparando los hilos... Y así los chicos amasan la Historia”, reproduciendo simbólicamente las tomas, insiste la joven.

Cristina, enfermera, de cuarenta y tantos, 7 hijos, integrante de la Comisión de Mujeres del Asentamiento El Tala, en su casa, la tarde del 12 de marzo de 1993, le relataba con palabras parecidas a nuestra compañera Liliana Guzmán ${ }^{11}$ :

Es como que se les va enseñando a los chicos que quieran a esta historia nuestra, porque hay que transmitirles el sentimiento de todo lo que nos costó. Nosotros tenemos un catecismo que lo hace la mamá catequista, empezamos en el 83 en nuestra diócesis; habla de la biblia, del éxodo, y vas a encontrar escrita nuestra historia en el éxodo. Porque la historia del éxodo del pueblo hebreo es la nuestra, tal cual. Entonces cuando nosotros llegamos con los chicos de catecismo a la parte esa de que el pueblo se libera, no hablamos del pueblo hebreo, hablamos de El Tala, del Santa Lucía, La Paz, el San Martín [los cuatro barrios de "las tomas del 82"]. Ese es el pueblo que se libera, el pueblo hoy, que no digan 'el tala, un barrio más', que sepan la historia de El Tala, que a esos chiquitos, esos mártires que murieron, no se los olviden.

Refería Cristina a los catorce niños muertos durante las tomas: "se murieron de diarrea en los asentamientos, de deshidratación, contaminados, mordidos por las ratas". Acontecimientos vividos por Cristina como una lucha contra la represión y la persecución, que fue la manera de ganar derechos:

Cuando vinieron los agrimensores en el año 86 fue tan poco lo que se tuvo que correr (de lo que habíamos marcado), porque queríamos tener todos los derechos. Porque siempre nos trataron de usurpadores, de ladrones, de lo que sea, y en la Municipalidad no podíamos pedir nada, ni médicos, no teníamos derecho ni a una cama de hospital, cuando decíamos de dónde veníamos. Si nos robaban o algún atropello, la comisaría nos decía ¿de dónde es? y nos decían ¡ah! mátense. Entonces no existíamos ni para la policía ni para los médicos, ni para la Muni ni para nada... Y ahora soy ciudadana del partido de Quilmes.

11 Liliana Guzmán (trágicamente desaparecida en la caída del avión de Austral en Fray Bentos, en 1997) formó parte de un grupo de estudiantes a los que orientábamos en esos años. 
Además de la toma en sí, el otro acontecimiento saliente fue el día de promulgación de la ley de expropiación:

Ese día estábamos ahí 2400 personas, esperando, sufriendo, pariendo esa ley de expropiación ...la emoción de haber sentido que se promulgaba la ley, es el día de hoy que me dan ganas de llorar. Y en vez de pararnos y aplaudir, empezamos a cantar el Himno Nacional. Porque nosotros no éramos habitantes de El Tala, éramos argentinos, éramos ciudadanos que luchábamos por un derecho. Para nosotros fue como parir esta ley, parir esta tierra, como haber hecho posible el sueño de tanta gente.

Y el recuerdo de Cristina parece mezclarse con el contraste de ese presente: "Pero ahora es otra cosa, ya se logró eso. La bandera y la virgen nunca faltaba en ningún asentamiento. Ahora hemos perdido la costumbre de poner la bandera en nuestras casas porque antes la bandera argentina flameaba casi todo el año en el barrio... la gente tiene mala memoria".

\section{La participación ciudadana porteña}

Hacia fin del siglo XX, ya con el gobierno aliancista de De la Rúa, un grupo de treinta vecinos y comerciantes minoristas de Caballito, en la ciudad de Buenos Aires, se reunían para "formar un corredor comercial a cielo abierto, con participación de todo el barrio, para mejorarlo". Lo llamaron Foro del Centenario. En rigor, no muy públicamente reconocían su militancia partidaria (Unión Cívica Radical, Frente País Solidario -Frepaso-, ambos de orientación general socialdemócrata, el primero perteneciente a un partido centenario en Argentina y el segundo surgido en la década del noventa, de alianzas de grupos de "centro-izquierda" y peronistas), pero el Foro era "de todos los vecinos".

Se nos requirió la coordinación de su primera reunión y les preguntamos "¿Qué es lo que se debería mejorar del barrio?” Y la respuesta más recurrente fue "la seguridad”. "¿Cuál es, para ustedes, la causa de la inseguridad?" Y la respuesta unánime fue: "las casas tomadas" "12, a lo que preguntamos: "Los habitantes de las casas tomadas, ¿no son vecinos del barrio? ¿O solo es vecino el propietario o el que alquila con contrato?" Como suele decirse, atronó el silencio y comenzaron a cruzarse las miradas.

"Claro, Ariel está diciendo que estamos discriminando", escuchamos comentar. Y, seguramente, en aras de la militancia de algunos de ellos en organismos de derechos humanos, a la próxima reunión invitaron a dos familias que vivían en una casa tomada, esta vez como "ciudadanos" del barrio.

$12 \mathrm{Al}$ igual que los terrenos intrusados, las casas "tomadas" por personas sin vivienda implican ilegalidad como indicador objetivo y atribución de conductas delincuenciales desde el imaginario urbano hegemónico. 
Muchos de esos vecinos tuvieron luego activa participación en los acontecimientos de diciembre de 2001; y también formaron parte de las asambleas que se constituyeron en uno de los resultados más salientes de esos acontecimientos, a las que se llamó "barriales", porque el barrio, en cuanto espacio público, era el escenario de manifestación, encuentro y re-conocimiento, pero que tenían como sustento para eclosionar la crisis económica, moral y política general. Sin embargo, cuando la fuerza de la movilización de esas asambleas mermó, el barrio resultó ser el destinatario de muchas de sus actividades.

\section{Épica del barrio mancha en la ciudad media provinciana}

El barrio Facundo Quiroga II se sitúa en un borde de la ciudad de Olavarría (“atrás de la ciudad", según Paola, una vecina), junto a otros conjuntos de viviendas sociales para sectores medios. Está compuesto por menos de diez manzanas de casas modestas, construidas por familias de desocupados con apoyo estatal a partir de la salida de la crisis de principios del siglo XXI. En realidad, para el caso de esta ciudad de rango medio (poco menos de 100000 habitantes), la crisis había comenzado a ser vivida de muy particular manera durante los años noventa. En otros trabajos analizamos la diferencia de vivir los despidos en un centro industrial como el olavarriense, cuya identidad emblemática era ser "la ciudad del trabajo" y la "capital nacional del cemento", que en otras escalas urbanas (Gravano, 2005b).

La bisagra del nuevo siglo agudizó aún más esta crisis, que tuvo sus efectos en la estructura, en los imaginarios y en la gestión de la ciudad. Luego de la explosión de 2001-2002, y ya en el gobierno de Néstor Kirchner (de extracción peronista), al que adhirió pioneramente el intendente radical Helios Eseverri, se produjo en Olavarría la primera implementación en el país del Programa de Emergencia Habitacional, como política de Estado, en articulación de los niveles nacional, provincial y municipal. Para eso, debían formarse cooperativas de vivienda.

Los movimientos sociales durante la crisis se focalizaban en provisión de satisfacción de necesidades básicas, y en la zona habían movilizado especialmente comedores barriales. La Federación Tierra y Vivienda venía realizando esto junto a reclamos y movilizaciones.

Uno de aquellos movilizados, Beto, a sus 16 años de entonces, lo recuerda así en 2015:

Yo nunca había trabajado y a partir de la movilización, trabajé, aunque no me gustaba, je, y el asunto de las cooperativas fue así: para cada cooperativa se necesitaban 16 personas (12 jefes de hogar y 4 desocupados). 'Van a tardar dos meses en organizarse' nos dijo alguien del Municipio. Era un día viernes... el lunes ya estaban armadas las cooperativas. Ese fin de semana se armaron nomás, pero el municipio 
tardaba en formalizar, entonces nos vinimos y empezamos a hacer que estábamos ya por construir, y no teníamos autorización ni depositada la plata para empezar. Vino el intendente, Eseverri, “¿qué están haciendo? No pueden empezar” "Vamos a trabajar, ¿qué vamos a esperar? tenemos pala, pico y la voluntad de la gente.

Se formaron en esa etapa diez cooperativas; y luego de la inauguración, en diciembre de 2004, se formaron diez más. El relato lo obtuvimos en talleres de un proyecto de extensión ${ }^{13}$ con un grupo de diez vecinos, trabajadores, todos participantes de aquella épica barrial.

Me acuerdo de Miriam, vecina del barrio, bajando un camión de cemento, un camión de bolsas de cemento, de las asambleas que hacíamos en el proceso de construcción del barrio con todos los cooperativistas. Me acuerdo mucho del día de la inauguración del barrio, cuando montamos todo un escenario ahí, en la esquina, en el principio... y en un momento salen unos vecinos del (barrio) Luz y Fuerza (lindante, de casas de mejor calidad), criticando.

Esa imagen de cuatro o cinco vecinos criticando la inauguración del barrio y nosotros festejando e inaugurando el barrio... Y la primera noche en la casa, con mi familia, con mi hermana y los nenes, charlando, en una sensación de seguridad, de estabilidad (Beto, 42, jornalero).

El asado que hizo el intendente... estaban todas las cooperativas, ahí nos juntábamos todos, asambleas permanentes (Castro, 42, jornalero).

La crisis es recordada hoy dentro de un contexto político y con políticos que son parte de aquella fundación barrial:

La situación en la que estaba el país no daba oportunidades como para decir 'ahorro, me compro una casa donde quiero o me compro un terreno y me hago la casa'. Eso era impensado. Llegó Néstor [Kirchner] y cambiaron cosas para nosotros. Yo me acuerdo cuando estaba criando a mis hijos, en el 2001, no tenía para darles de comer, estaba viviendo en una casa prestada, tenía agua de pozo, mis hijos con parásitos. Ahora tengo un lugar, tengo tierra, puedo hacer quinta. A los que nos quedamos (en el barrio) realmente nos cambió (Paola, 45, jefa de hogar).

Dos episodios reflejan el modo de gestión del estado municipal:

Cuando surgió el tema de qué nombre ponerles a las cooperativas, les queríamos

13 El proyecto se llama Memorias Barriales en Acción, con la participación de Bárbara Galarza, Suyai Compagnon, Florencia Otermín, Daiana Mignogna y Natalia Mengochea del Proincomsci-Unicen. 
dar identidad: La Ilusión, El Progreso, Unión y Esfuerzo. Y lo primero que nos dice Eseverri cuando armamos la cooperativa ese viernes, me dice: 'bueno, acá no me vengan con nombres raros, pónganle 1, 2, 3, 4 y 5". "Y la orden de Eseverri fue que a las cooperativas no las integrara ninguna mujer, y nosotros sí queríamos, ya que en todo el trabajo territorial nuestro en los comedores barriales, el mayor peso lo tenía la mujer, los hombres no (porque) la tendencia del hombre era la de encerrarse, de no sentirse dignificado por no poder llenar la olla... la que ponía el cuerpo, la que salía a patear la calle era la mujer... (Beto).

"Claro, si Eseverri en la inauguración dijo que éste era un barrio de negros" se oyó recordar y se vio asentir por el grupo de vecinos. "Y yo soy negro, ¿y qué?" (Castro, 41).

Él es negro, pero tiene el alma blanca (Horacio, 50).

No, nosotros antes éramos negros, ahora ya no somos más negros, porque tenemos casa (dijo otra vecina).

Es que la marca de este barrio, para la visión del resto de la ciudad, es el de ser uno de los más estigmatizados. Sabido es que en estas ciudades del centro bonaerense no se registra la existencia de villas miseria, pero sí el fenómeno de discriminación análogo en el imaginario hegemónico, al que dimos en llamar barrios "mancha" (Gravano, 2005b), en el que el objeto de la estigmatización eran este tipo de conjuntos de viviendas de provisión estatal. Esta señalización no es solo parte de la identidad de estos lugares, sino que constituiría también parte de su épica en el presente, reforzada por relatos de hitos vividos como marcas barriales: "Esa razia (de la policía) fue tremenda, tiros y los golpes, espantoso, se habló muy poco en la ciudad, pasaban todos los milicos apuntándonos, y nadie había hecho nada, querían limpiar el barrio, hubo baleados adentro del barrio y de eso, nadie dijo nada" (Paola).

"Y de ahi es cuando se hizo de mala fama el barrio" (Fany, 51).

Y se cumple con la narrativa común de la discriminación sobre el barrio mancha: "Los remises no quieren entrar. Es como que nos tienen bronca, decís que sos del Facundo Quiroga II y... es el barrio de los negros" (Fany), en coincidencia con las mismas palabras del intendente al inaugurar el barrio.

\section{Sentidos, procesos y relaciones}

Hemos apelado a combinaciones de una diversidad de contextos de registro y enunciación: entrevistas, observaciones, fuentes secundarias, investigaciones propias y ajenas, intervenciones propias y trabajo de campo de equipos que dirigimos. La opción de mostrar retazos diversos, escalas espaciales de lo urbano, también de amplio espectro y momentos diferentes, obedeció al propósito de establecer un cuadro amplio, si bien no exhaustivo de nuestro tema, las épicas barriales, sus posibles recurrencias y diferencias, sin pretender - ex profeso- compararlas o generalizar, pero sí establecer un mínimo de consenso para su validación como objeto de estudio. 
En una visión sintética, en las viñetas pueden señalarse recurrencias con respecto a 1) las narrativas y sus contenidos, 2) los procesos histórico-estructurales a que refieren, y 3) las relaciones con respecto a lo público y lo político.

\section{Narrativas, contenidos y sentidos}

La secuencia más común es la que comienza con una situación inicial crítica, caracterizada por la carencia (o encarecimiento) de consumos colectivos urbanos (luz, seguridad y principalmente vivienda), incluida la recurrencia de imágenes de baldío pre-urbano. Luego seguiría con las hazañas imbuidas de componentes específicos: movilización y organización colectiva que responde a una visión estratégica y a tácticas particulares, luchas que incluyen negociaciones y astucias de procedimientos, pero básicamente la "sociabilidad" y masividad del movimiento como un ingrediente central. Heroicidad y martirologio conforman también -en la representación de los actores- la identidad de los movimientos y su sentido de haber jalonado esa identidad en términos "históricos", superando en términos amplios el ámbito local barrial, ya que simbólicamente la épica concibe lo particular en un sitial de trascendencia.

Estas épicas se construyen alrededor de un momento de problemas y de construcción colectiva de soluciones, pero con el valor agregado de esa significación trascendental que adquieren las luchas, tanto en términos personales cuanto colectivos, por el contraste entre esas dos situaciones, la inicial crítica y la del auge de la movilización y sus logros. No obstante, un tópico es el declive de la "participación", de la plenitud, del esplendor como se vivió la epopeya, en contraposición con una actualidad (del momento de expresión del relato) vivida como desmovilización e individualismo, aún a pesar de que las movilizaciones del presente (del momento en que los actores narran) tengan intensidad y notoriedad.

Esta especie de síndrome de la ola marina que acompaña, como eje narrativo, al desarrollo de los movimientos barriales, parecería reflejar recurrentes etapas fundacionales de mayor plenitud, protagonismo y participación comprometida, seguidas de una declinación ulterior (tal como se muestra en algunos de los testimonios de las viñetas). Podríamos preguntar, ¿en qué medida es efectivamente real ese proceso narrado? o ¿por qué esa declinación parece constituirse en un tópico de esa narrativa?

Una hipótesis que ensayaría respuestas a estas preguntas podría rondar alrededor de asunciones de tipo universalista con respecto a una posible o supuesta dinámica pendular inherente a las movilizaciones sociopolíticas, parejas al carácter efímero de estos movimientos no clásicos, o a un impulso inicial realmente 
existente como pleno, que luego se perdería. Desde ahí, se respondería afirmativamente al interrogante sobre la "realidad" de los contenidos de estas narrativas barriales y se posibilitaría establecer la generalidad de la lógica de la ola marina.

Podrían ensayarse explicaciones fácticas e históricas, como la del "repliegue en los barrios" durante las dictaduras (Romero, 1985), a la que podríamos agregar una posible interpretación del acotamiento a los barrios de las asambleas poscrisis del 2001 debido a los efectos del modelo neodesarrollista inclusivista de los gobiernos kirchneristas. En forma semejante, la argumentación de la lógica del declive por los logros de las luchas la encontramos en boca de militantes sociales.

No obstante, más allá de que se puedan efectuar preguntas sobre el contenido de verdad de las narrativas, proponemos otro tipo de desafío interpretativo, consistente en tomar el declive como una parte de la épica. Al menos, hay que aceptar que el síndrome de la ola es recurrente en la narrativa. Su validación puede darse por dos líneas teóricas a desarrollar (que aquí sólo esbozamos): una de tipo individual, que consiste en atribuir la imagen de la decadencia del movimiento a que las movilizaciones del presente del actor no lo incluyen, o, dicho de otra manera, ese actor, ese narrador, ya no se moviliza como lo había hecho cuando era protagonista, las movilizaciones de él son "las de antes". Sería una argumentación de tipo individual y coyuntural.

La segunda posibilidad es más estructural que coyuntural, y trasciende lo individual, pues se situaría como negatividad dialéctica dentro de procesos semiótico-históricos, constitutivos de la memoria social. Algo así como la "deshistorización" del barrio "de antes" que encontramos y analizamos en términos de una época base que se constituye en el eje de una identidad producida ideológicamente a partir del no control de las condiciones de existencia de los sujetos (Gravano, 2003). La época base se constituye en una épica o se construye con épicas a partir de la lucha, el heroísmo del esfuerzo propio, individual y colectivo, y la victoria del logro perseguido, pero fundamentalmente porque es una época sentida, vivida como propio y cara en lo afectivo.

La épica barrial, como todo relato mítico, entonces, se compondría del recuerdo, de la memoria, de la representación de un pasado heroico para actuar y posicionarse en el presente y, por lo tanto, para valorar y afrontar un problema, una contradicción de la cotidianidad del presente. De esta manera, el propio declive podría actuar semiótica e históricamente como la razón de ser de la épica, sea este declive real o solo imaginado por los actores. Junto a la lógica necesidad de ver o descubrir lo que la deshistorización encubre, proponemos agendar la interpretación de lo que descubre, de lo que "abre de nuevo", al decir de Ernesto De Martino, tanto en términos imaginarios cuanto estructurales (Gravano, 2015). 


\section{Los procesos histórico-estructurales}

Hacia esa agenda de descubrimiento difícilmente se pueda llegar reproduciendo la reproducción, que es lo que nos sugiere sortear el antropólogo italiano y a lo que apuntamos de acuerdo con el eje de la negatividad estructural ${ }^{14}$, cuyo componente central es la apropiación del excedente urbano.

La explicación estructural establece que la provisión de parte del Estado de consumos colectivos de base para la reproducción de la fuerza de trabajo subsidia al capital, que así se constituye como tal mediante el proceso de urbanización, aliviado de garantizar esa reproducción, por medio de la universalización "ciudadana" de la solvencia del sistema urbano. Sin embargo, la ciudad emerge como un producto material y social total para la ciudadanía abstracta, a la vez que es consumida en forma desigual por las clases sociales concretas. No es casual que los movimientos sociales urbanos, entre los que se destacan los barriales, se erijan reivindicando el "derecho a la ciudad".

Cuando Manuel Castells (1987) los define como resultado de la contradicción entre la lógica de acumulación del capital y la relación política de fuerzas, tomando como punto de partida su definición del sistema urbano como funcional a la reproducción de la fuerza de trabajo, mediante el abastecimiento de esos consumos colectivos, establece que emergen en la ciudad contradicciones secundarias con respecto a la principal, entre capital y trabajo, que dan lugar a este tipo de luchas en el ámbito de la reproducción. Las críticas que recibió fueron, en primer lugar, que reducía el sistema urbano a los consumos y a la reproducción necesaria de la fuerza de trabajo y, de esta manera, desconocía el rol político de los movimientos clásicos (como los partidos) dentro o a la par de los movimientos "nuevos", y que al utilizar una noción de consumo colectivo reducida a la provisión del Estado, no consideraba a las luchas urbanas como parte de la luchas de clases. (Lojkine, 1979)

En forma alternativa, Tilman Evers, junto a Müller-Plantenberg y Sepessart (1982), colocan las luchas urbanas en la esfera de la reproducción y el consumo, pero argumentan que no están fuera de la lucha de clases. Incluso consideran las luchas en los barrios como inmersas en los intereses y las estructuras de clase, por más que estos contextos urbanos no resulten ser homogéneos en cuanto a la conformación social. Además, verifican esto en Latinoamérica, en la época en que las dictaduras habían cerrado los canales de representatividad política y sindical, y los barrios constituyeron escenarios de luchas por los consumos y la reproducción, con actores sociales que se erigieron en sujetos políticos de importancia (p.e. la mujer) dentro de esas luchas. "No hay lucha de clases que no sea a la vez una lucha por las condiciones reproductivas de la clase obrera; por ende, tampoco hay lucha por mejores condiciones de vida que no sea parte de la lucha de clases" (Evers, Müller-Plantenbertg y Spessart, 1982, p. 716).

14 Concepto desarrollado por René Lourau (1988), a partir de la dialéctica hegeliana y marxista. 
A pesar de estos posicionamientos de fondo (y los que citamos en la primera parte de este trabajo), en el imaginario político-institucional y académico tienen más vigencia concepciones de ciudad, ciudadanía y espacio público en términos abstractos e idealistas, encubridores de la vida concreta de los mortales en la ciudad.

Si bien cuando se invoca a la ciudad que "muere" (Castells, 1974) o a la ciudad que "es ante todo el espacio público" (Borja, 2014, p. 111), se implica la cuestión del derecho ciudadano y esta es una visión que prepondera como plataforma crítica para reivindicar ese derecho con respecto al no cumplimiento de la ciudad misma en su misión de "hacer libres a los hombres"; se rebautiza hoy la teoría de la marginalidad con la dicotomía exclusión/inclusión (para mencionar la más en boga). De igual forma, se oscila entre el optimismo idealista y funcionalista de Saskia Sassen sobre la ciudad global (Sassen, 1999), las hipercríticas ambulatorias de Manuel Delgado sobre el espacio público (2002) ${ }^{15}$ y los "espacios de esperanza" del consecuente David Harvey (2007), estos últimos (entre otros muchos) con ponderación de los movimientos sociales como alternativos a la globalización dominante. Asimismo, en una reciente encuesta entre urbanistas, a la pregunta sobre las dificultades mayores del mundo urbano contemporáneo, las referencias más recurrentes fueron sobre "el espacio público" (Sevilla, 2012).

Consideramos que, en el fondo, la representación (o cosificación) de lo público como el espacio público se ha tornado riesgosa para la mirada de la negatividad hacia lo urbano que proponemos, y que definimos como lo que "la ciudad" omite en los discursos (los sujetos individuales y sociales concretos, en aras del concepto de ciudadano abstracto) y omite en sus prácticas, o modos de "hacer ciudad", como suele repetirse, sobre todo la apropiación del excedente urbano, que es lo que se pone en juego en la totalidad de nuestras viñetas.

\section{Dialéctica de lo público vivo}

Constituido lo urbano a partir de la apropiación del excedente de alimentos en los imperios, ciudadesestados esclavistas de la Antigüedad, a partir de la centralidad del intercambio mercantil entre oasis y el dominio de estamentos surgidos de esa misma centralización (burócratas, guerreros, sacerdotes), lo público emerge en el espacio profanus (delante del templo) y a la vez paradójicamente se sitúa material y simbólicamente dentro del espacio sagrado del poder concentrado simbólica y materialmente: los edificios "públicos" (templo y palacio, residencia del Estado).

15 Ver una crítica a la postura de Delgado en Cucó (2004). 
El ciudadano pasa a ser la categoría que identifica y nomina lo que los seres humanos son por pertenecer a ese poder estructural e imaginario concentrado (amparado por la autoridad ideológica del templo) llamado ciudad. La paradoja de esas ciudades antiguas es que incluían materialmente a los esclavos de los cuales dependían para su producción, pero no los contenían en su imaginario identitario, por no ser ciudadanos de esa ciudad.

Será la mirada moderna del idealismo filosófico de Immanuel Kant la que siente las bases de la concepción hegemónico-burguesa de lo público. Su ideal liberal articula con dos formas de ver lo público: la que refiere a la razón de Estado y la razón por sobre el Estado y la que ve el bien común como el que otorga derecho a la libertad de los privados. Se impone así la visión de un orden natural libre de coerción hacia el privado y a la vez la necesidad de un límite a esa libertad. Coincide con la necesidad del control, de parte de las burguesías, de las mismas acciones burguesas. El pensamiento liberal moderno coincide con estas asunciones, donde el derecho público de la sociedad civil estará por encima del Estado para regir la prevalencia de la razón y será la sociedad civil la que controle al Estado para que las leyes se cumplan de acuerdo con los principios éticos de lo público, en función de una razón trascendente.

Esta perspectiva de algo abstracto por encima de la realidad contradictoria material, rigiéndola en función de valores también abstractos, la sostiene Hannah Arendt (2007) cuando reivindica la polis, como ámbito del hablar y actuar en común donde rigen la libertad y la igualdad y su tarea es crear y mantener lo político, de acuerdo con la consigna del "derecho a tener derechos" y a ser tratados como libres e iguales en la esfera pública, no en el ámbito de lo doméstico privado, que es donde se satisfacen las necesidades materiales, el oikos. Arendt parecía, por un lado, fascinada por el ideal griego del ágora, pero no ponderaba las desigualdades dentro de la ciudad-estado que señalamos recién y atribuía la crisis del espacio público en la Modernidad a que éste había sido usurpado por la imponente llegada a la escena política de los "problemas sociales del trabajo y de las necesidades" (Arendt, 2007, p. 58), lo que quitaba a los hombres la posibilidad de debatir y actuar políticamente.

Desde un prisma similar a Kant, Jürgen Habermas (1994) distingue entre Estado y esfera pública y prioriza la comunicación como el canal de expresión de esta, desde donde se ejerce crítica y control al Estado, que debe bregar por el "bien público". La "esfera de lo público" es la mediadora entre la sociedad y el Estado, la publicidad es la que permite el control democrático del Estado y la sociedad civil resulta ser el espacio genuino de la autonomía privada frente al Estado. Parece sinonimizar la sociedad civil con los privados y naturalizar el poder de la burguesía respecto a la reproducción: "en tanto que la reproducción de la vida [en el capitalismo] ha entrado en la naciente economía de mercado y en tanto que rebasa las limitaciones del poder privado" (Habermas, 1994, p. 105), y sigue a Kant en cuanto a que una racionalidad razonable debe prevalecer en el manejo del Estado, en bien del interés general, todo de acuerdo con el ideal de una sociedad culta formada por personas privadas, iguales y libre-pensantes. 
Es menos conocido -o menos citado- el concepto de lo público de Carlos Marx ${ }^{16}$, cuando se centra en el análisis de la escisión mundana entre sociedad civil, por un lado, el hombre como individuo viviente por el otro, y el Estado político en tercer lugar. En estas relaciones, el hombre como ciudadano es la contradicción entre el interés privado y el interés general, común, de lo público.

Marx ubica a la sociedad civil como resultado de la revolución parcial de parte de la burguesía y a la vez como traba de la emancipación humana. Por eso, analiza la Declaración de los Derechos del Hombre de 1791 y su concepto de libertad, donde emerge la contradicción entre lo público y lo privado. La libertad, es "el derecho de hacer y de tender a todo aquello que no perjudique a los demás", pero "se trata de la libertad del hombre como mónada aislada, replegada en sí misma” (Marx, 1936, p. 84). Y concluye:

La aplicación práctica del derecho de libertad, es el derecho de la propiedad privada" (íbid.), que "es, entonces, el derecho de gozar y disponer de la propia riqueza arbitrariamente sin cuidarse de los otros hombres, independientemente de la sociedad; es el derecho al egoísmo [que], con su aplicación, constituye el fundamento de la sociedad civil (p. 85).

El ser humano egoísta es algo que aparece dado, el "resultado pasivo", de la sociedad disuelta, algo natural, objeto de certidumbre inmediata. Se escinde así al individuo como miembro de una sociedad civil y como ciudadano. No obstante, en ambos conceptos abstrayendo a las clases sociales a las que pertenecen los seres humanos concretos.

Sólo cuando el real hombre individual recoge en sí mismo al ciudadano abstracto, y como hombre individual se convierte en ser social en su vida empírica, en su trabajo individual, en sus relaciones individuales, sólo cuando el hombre reconoce y organiza como fuerzas sociales sus forces propres y por eso no separa más la fuerza social en forma de fuerza política, sólo entonces se cumple la emancipación humana (Marx, 1936, p. 103).

Lo público, para este teórico, se sitúa en dos tensiones: en el seno de las contradicciones históricas planteadas por el poder burgués, universalista en sus invocaciones, pero no universal en sus efectos, y el eje en la necesidad histórica de la emancipación humana, a lo que esa revolución y su Estado correspondiente se acercan parcial e interesadamente, ocultando la brecha entre esas invocaciones a los valores del bien común y la razón moral en abstracto y el ejercicio del dominio particular de clase.

16En su ensayo La cuestión judía, de 1840, Carlos Marx aborda de fondo el tema de la separación del Estado de la religión y llega así a la cuestión de lo público. Sin embargo, aprovecha y apunta a la cuestión humana radical, contradicha por las relaciones de poder en el capitalismo. 
El sentido comunitario de la emancipación humana, del communitas de Marx, y las fuerzas propias podrían ser el equivalente al trabajo "sin atributos", trabajo plenamente humano, o trabajo vivo, en contradicción con la apropiación de valor por el capital, o trabajo muerto ${ }^{17}$.

¿Podríamos hablar de lo público vivo, en este mismo sentido de no alienación de clase, a partir de lo que tomamos de Marx? Implicaría considerarlo como construcción histórica en sus contradicciones internas, de acuerdo con su bidimensionalidad material y simbólico y no como una entelequia abstracta y sobre-histórica (razón, moral) fuera de las significaciones terrenales. Lo público vivo puede desplegarse como abierto al futuro en sus posibilidades de transformaciones que incluyan su propia problematización.

Lo público vivo es una reivindicación para esas transformaciones, a partir de la brecha entre su invocación general (como lo público abstracto) y la realidad de su apropiación privada. Puede permitir superar la mera descripción del espacio público como "escenario de disputas", desde la teoría de los juegos o asunción de la conflictividad como disputa inter-pares. De esta manera, forma parte necesaria de la apropiación del excedente urbano, o lo que podemos caracterizar (siguiendo con la paráfrasis sobre el trabajo) como lo público muerto (convertido en valor) de lo urbano. Por lo tanto, nos obliga a partir -para el análisis- de lo que el concepto de ciudadano encubre: las clases sociales y su ponderación como eje estructural.

Como primer hipótesis "de llegada", podríamos establecer que en nuestras viñetas épicas lo público vivo se constituye en la ciudad reivindicada y peleada como derecho a su uso por los movimientos, en la narrativa épica que, haciendo un racconto, va de la situación crítica a los logros y los valores desatados en esos procesos:

- De la situación crítica: del no acceso al servicio eléctrico del fomentismo; a la vivienda digna y al sistema de consumos y servicios, pero sobre todo a la persecución constante, en el caso de las villas miseria; de la vivienda y la tierra, en el caso de las tomas del conurbano, y de la sobrevivencia más básica en el caso de los desocupados de la ciudad media.

- A los logros concretos producto de las movilizaciones: la provisión de los servicios como respuesta estatal a barrios y villas metropolitanos, los títulos de propiedad por medio de la legislatura y el poder ejecutivo provincial de los terrenos tomados (en el conurbano), y el apoyo nacional y municipal a las cooperativas de autoconstrucción de viviendas, en el caso del barrio de la ciudad media.

- Pero también lo vivo se da a partir de los valores simbólicos construidos por el proceso mismo de las movilizaciones, en la ciudadanía construida y consciente ("somos ciudadanos"), expresada con contundencia en las narrativas y presente en todos los casos: en la alianza con el poder técnico (para la colgada masiva del fomentismo), en las ocupaciones y construcciones mismas de las villas y en el cambio en la reconversión de quienes habitaban las casas tomadas del barrio como ciudadanos, en la organización, la planificación y el "hacer barrio" de las tomas, y en la recordada e invocada plenitud de la participación mediante el esfuerzo individual y de los barrios creciendo "a pulmón", esto es: mediante el trabajo vivo.

17Tomamos el concepto desarrollado por Marx en El Capital (1971 [1867]) y lo hemos vinculado a lo urbano-barrial en Gravano (2003). 
Todo lo que implica, en síntesis, producir ciudad como algo vivo, no solo al acontecer de hecho, sino al narrarlo desde el derecho a la ciudad, al actualizarlo incluso como contraste con el presente de cada naración, tipificado como des-movilización y declive.

En contrapartida dialéctica, podríamos hablar de lo público muerto de la segregación socio-espacial, de la privatización de lo público y la expoliación urbana en una dimensión estructural, marcadas por la apropiación de la plusvalía urbana ${ }^{18}$ de parte del capital subsidiado por el estado en la provisión del sistema de servicios públicos (incluida la misma empresa de electricidad), desigualmente distribuido, que fue la causa de las movilizaciones en el caso del movimiento fomentista; por la explotación de la fuerza de trabajo radicada en las villas, marginalizadas pero cercanas a las fuentes de trabajo y, por lo tanto, aptas para convertirse en el clásico ejército industrial de reserva en los flujos cíclicos de las economías dependientes y ser funcionales a la estabilidad y suba de la tasa de ganancia, o para ser expulsadas, como se muestra en el caso de las tomas de terrenos; y también de la discriminación y la autodiscriminación ambigua ("éramos negros"), en una dimensión simbólica, que se detecta en el caso del barrio periférico de la ciudad media.

Una dimensión (la simbólica) que podemos verificar en los sentidos de ciudadanía muerta que se desencadenan en torno a asunciones de tipo vecinalista de parte del Estado y de los actores sociales en los procesos participativos invocados desde un sentido de lo público abstracto, que suelen acotarse a lo vecinal como modelo idealizado de vida. Es lo que hemos llamado la idealidad de lo barrial, como aquella variable presente en los imaginarios que deshistorizan la vida barrial de sus condiciones estructurales, donde al barrio se lo representa como abstracto, homeostático e idealizado en su pureza y armonía (Gravano, 2003, 2015).

Los procesos participativos institucionales se edifican en general sobre la base de este modelo homeostático de concebir lo social, lo urbano y lo barrial, asociado a la ética abstracta de la sociedad civil y del espacio público.

La negatividad de lo urbano nos da cuenta de aquella omisión del sujeto concreto que se le escapa a esa concepción de lo público y de la ciudadanía en la que se termina apelando a la categoría de "vecino" como algo más "auténtico", más "puro", más aséptico respecto a la política, y que es lo que se esgrime en los intentos institucionales de participacionismo inducido ${ }^{19}$.

Los procesos "participativos" (como el de la viñeta porteña), de auge durante la posdictadura y, sobre todo, en el primer neoliberalismo en democracia (Menem, De la Rúa), tomaron como bagaje conceptual y moral este sentido de lo público muerto, invocador de lo ciudadano ahistórico. Por este motivo, resulta

18 Se define plusvalía urbana como el valor de cambio que se le agrega en el mercado a un espacio a partir de la instalación de servicios de consumos colectivos, equipamientos e infraestructura (sanitaria, de transportes, comunicación, asfalto, energía, seguridad, salud, educación, etc.).

19Las bases teóricas del vecinalismo hegemónico las estudiamos detenidamente en Gravano (2005a). 
destacable que el mismo discurso participativista y relativista se plasmara en el discurso de Mauricio Macri (segundo neoliberalismo en democracia en Argentina, de poder distrital en la ciudad de Buenos Aires desde 2007 y a partir de diciembre de 2015 en el nivel nacional) durante sus campañas y no se institucionalizara durante sus gobiernos, junto al trueque de la invocación a los ciudadanos por el más recurrente de "lus vicinus" ${ }^{20}$.

\section{Hacia lo político vivo}

El intento inicial de acercarnos a los sentidos políticos de las narrativas barriales nos obliga a asumir la distinción entre la política en su acepción estricta (lo que cada sociedad establece que es "la política", como sistema, ámbito, conjunto de instituciones y procesos normativos y formales instituidos como tales), y lo político en un sentido amplio, que desde ya incluye la política como sistema (partidos, organizaciones, Estado), pero también abarca los contenidos y valores políticos de aquellos procesos sociales que no son considerados estrictamente políticos. Dentro de la tensión entre ambos sentidos, se encuentra nuestra emergencia, en los movimientos sociales barriales, de las "acusaciones" de que "se metió la política", "acá no queremos política”, típica de las organizaciones intermedias, esto es: el apartidismo como sinónimo de apoliticismo. Ya Matthew Crenson (1983), en su Neighborhood Politics (Las políticas del barrio) había observado esta diferencia, resaltando el sentido de lo político dentro de la práctica cotidiana y al valor político de todo lo que se hace en el barrio, no restringido a las instituciones vecinales ni estrictamente políticas.

Si consideramos a lo político como el proceso estructural implícito y de lucha explícita por el acceso a la producción de rupturas y transformaciones sociales, para nuestros propósitos de analizar los sentidos políticos de los movimientos barriales plasmados en sus épicas, es importante tener en cuenta los contenidos y ejes analíticos de las narrativas como una superficie indiciaria que permita proyectar hipótesis para estudios de caso en profundidad.

En todas las viñetas épicas se alude a la política en sentido estricto, cuando se alude -con distintas valoraciones- a la militancia en partidos políticos. No obstante, el valor fundamental está dado por lo político del barrio en un sentido amplio, en la dimensión estructural de lo urbano, en la negatividad del proceso por el cual las contradicciones de clase producen los movimientos reivindicativos de lo público vivo en lucha contra lo público apropiado, privatizado, muerto.

Por eso, la segunda hipótesis de llegada que arriesgamos proyecta la dialéctica de lo vivo/muerto hacia lo político. Definimos a lo político muerto como el resultado del poder y el dominio legitimado para la explotación de clase, a partir de la apropiación de vida (material y simbólica) de lo humano, en el sentido que da Marx a la "emancipación humana". Es lo que obtura, por medio del sistema político republicano-

20Dicho esto ex profeso en la jerga de algunos recoletos vecinos de Buenos Aires (ver nuestro "Vecinos o ciudadanos" [Gravano, 2011]). 
capitalista (no solo neoliberal ni dictatorial), la reproducción social como vida plena humana y sobre todo como reproducción básica (los consumos colectivos) y, por lo tanto, impulsa a los movimientos sociales como transgresores y transversales a la legalidad política formal, por necesidad y por lo que el sistema representativo en los hechos no provee.

La base de los movimientos es el desarrollo pleno de las fuerzas propias populares, con su poder alterno, o lo que podríamos llamar lo político vivo, porque, en realidad, la bisagra de la apropiación de poder por medio de la hegemonía es posible porque hay un valor alterno antes que subalterno, un poder vivo, lo político vivo.

\section{Conclusiones}

Como se vio en las épicas mostradas, lo que está en juego es la apropiación del excedente de vida que implicaron las luchas, cuando se vivieron y cuando se las narra, en las que lo político vivo estaría indicado por las rupturas con lo dado tanto fáctico cuanto normativo de las movilizaciones vividas como hazañas heroicas. Luchas por lo público desde la conciencia del derecho ciudadano, desde la participación y la movilización colectivas, la organización, las estrategias y, por supuesto, la militancia, aún la que se oculta por supervivencia o por astucia táctica, en oposición a lo político muerto, que estaría representado por la apropiación del sentido amplio y pleno de lo político por el tabique formal con que se lo concibe desde el apartidismo apoliticista, encepado en la etiqueta "los políticos" o "la política" (en sentido estricto).

Postulamos, en conclusión, la emergencia del epos barrial como objeto de estudio significativo, porque constituye un tópico de las identidades y los movimientos barriales. En estas narrativas es posible registrar, en términos políticos, el movimiento mismo, visto y actualizado por sus actores-autores.

La base de este objeto es lo histórico estructural-significacional en una relación de totalidad que implica interrogar por los procesos de valorización territorial y urbana, explotación económico-productiva y negatividad ideológico-institucional, en torno a la apropiación de un excedente económico-urbano, y públicopolítico que lo sostiene en su necesidad de reproducción.

Lo que proponemos es aguijonear con estos ejes las narrativas de los movimientos sociales en general, para analizar la relación entre prácticas y representaciones que trasciendan la mera descripción que empieza y termina estableciendo un "campo de disputas".

Las épicas barriales muestran la dialéctica entre lo público vivo y lo público muerto y no constituyen en sí ninguna "otra política", como a veces suele proponerse, sino que son producción ideológico-simbólica de lo político vivo. A la vez, este registro no implica solo describir lo que se mueve, sino también lo que no se "mueve" y debería o podría hacerlo, o por qué no lo hace, y detectar el movimiento cuando no es notorio, 
en su latencia, y en su negatividad y contradicciones internas respecto a lo estructural de cada contexto y de su heterogeneidad interna.

En los contenidos épicos, el auge y declive -como épocas simbólicas opuestas- son parte de una saga que contiene en sí misma la dialéctica del logro y la frustración y del intento de reapropiación del excedente de vida que conforma la relación entre lo público y lo político vivo y lo público y lo político muerto, que implica la lucha por una reproducción no garantizada en aras de la "solvencia anticipada" del capital, con lo cual nos acercamos nuevamente al concepto de emancipación humana y ya no tan solo social o política, como propone Marx.

\section{Referencias bibliográficas}

Acción. (1 de noviembre de 1970). Vida en villas. Acción, p. 5.

Arendt, H. (2007). La condición humana. México D.F.: Paidós.

Bartolomé, L. (1984). (comp.) Relocalizados. Buenos Aires: Ediciones Instituto de Desarrollo Social.

Bellardi, M. y De Paula, A. (1986). Villas Miseria: origen, erradicación y respuestas populares. Buenos Aires: Centro Editor de América Latina.

Borja, J. (2014). Revolución urbana y derechos ciudadanos. Buenos Aires: Café de las Ciudades.

Castells, M. (1974). La cuestión urbana. Madrid: Siglo XXI.

Castells, M. (1987). Movimientos sociales urbanos. México D.F.: Siglo XXI.

Crenson, M. A. (1983). Neighborhood politics. Cambridge: Harvard University Press.

Cucó, J. (2004). Antropología Urbana. Barcelona: Ariel.

Dávolos, P., Jabbaz, M. y Molina, E. (1987). Movimiento villero y Estado (1966-1976). Buenos Aires: CEDAL.

Delgado, M. (2002). Etnografía del espacio público. Revista de Antropología Experimental, 2. Recuperado de http://revistaselectronicas.ujaen.es/index.php/rae/article/view/2111/1853

Evers, T., Müller-Plantenbertg, C. y Spessart, S. (1982). Movimientos barriales y Estado. Luchas en la esfera de la reproducción en América Latina. Revista Mexicana de Sociología, 44(2), pp. 703-756.

Gravano, A. (2003). Antropología de lo barrial. Buenos Aires: Espacio Editorial.

Gravano, A. (2005a). El barrio en la teoría social. Buenos Aires: Espacio Editorial.

Gravano, A. (2005b). Imaginarios sociales de la ciudad media: emblemas, fragmentaciones y otredades urbanas, estudios de Antropología Urbana. Tandil: Red de Editoriales de Universidades Nacionales.

Gravano, A. (2011). ¿Vecinos o ciudadanos? El fenómeno NIMBY: participación social desde la facilitación organizacional. Revista de Antropología, 54(1), pp. 191-230.

Gravano, A. (2015). Antropología de lo urbano. Buenos Aires: Editorial Café de las Ciudades.

Guber, R. (2015). Villeros, o cuando querer no es poder. En A. Gravano (ed.) Antropología de lo urbano (pp. 263-310). Buenos Aires: Editorial Café de las Ciudades.

Habermas, J. (1994). Historia y crítica de la opinión pública. México D.F.: Gustavo Gili. 
Harvey, D. (2007). Espacios de esperanza. Madrid: Akal.

Hermitte, E. y Boivin, M. (1984). Erradicación de villas miseria y las respuestas organizativas de sus pobladores. En L. Bartolomé (comp.), Relocalizados (pp. 7-22). Buenos Aires: Ediciones Instituto de Desarrollo Social.

Lojkine, J. (1979). El marxismo, el Estado y la cuestión urbana. México: Siglo XXI.

Lourau, R. (1988). El análisis institucional. Buenos Aires: Amorrortu.

Marx, C. (1936 [1840]). La cuestión judía. Buenos Aires, Biblioteca Dialéctica.

Marx, C. (1971 [1867]). El capital. México: Fondo de Cultura Económica.

Oszlak, O. (1991). Merecer la ciudad, los pobres y el derecho al espacio urbano. Buenos Aires: Humanitas. Portillo, A. (1991). Ciudad y conflicto, un análisis de la urbanización capitalista. Montevideo: Compañeros. Propp, V. (1983). El epos heroico ruso. Madrid: Fundamentos.

Romero, L. (1985). Sectores populares, participación y democracia. Revista Pensamiento Iberoamericano, 7. Sassen, S. (1999). La ciudad global. Buenos Aires: EUdeBA.

Sevilla, Á. (coord.) (2012). Conflictos de la ciudad contemporánea: un sondeo internacional. Urban NS03, 107-137.

Topalov, C. (1979). La urbanización capitalista. México D.F.: Edicol. 
